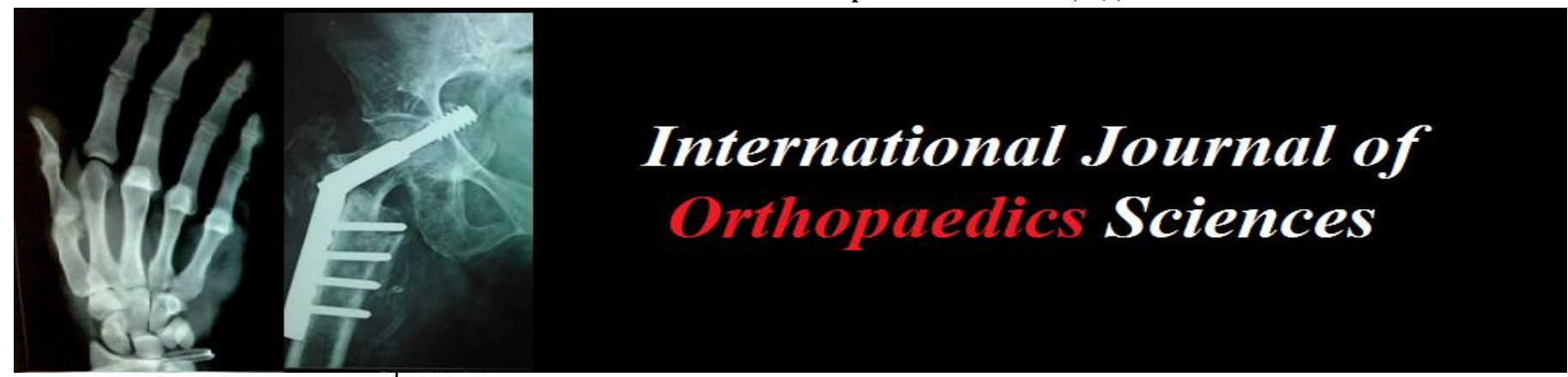

ISSN: $2395-1958$

IJOS 2019; 5(1): 75-79

(C) 2019 IJOS

www.orthopaper.com

Received: 10-11-2018

Accepted: 14-12-2018

Dr. SU Sivaprakash

MS Associate Professor,

East Point College of Medical

Sciences, Bengaluru, Karnataka, India

Dr. R Muralidhar Reddy

DNB Assistant Professor,

East Point College of Medical

Sciences, Bengaluru, Karnataka,

India
Correspondence

Dr. R Muralidhar Reddy

DNB Assistant Professor,

East Point College of Medical

Sciences, Bengaluru, Karnataka,

India

\section{Functional outcome of comminuted intra-articular distal radius fractures managed by Ligamentotaxis}

\author{
Dr. SU Sivaprakash and Dr. R Muralidhar Reddy
}

DOI: https://doi.org/10.22271/ortho.2019.v5.i1b.17

Abstract

Distal radius fracture is one of most common fractures seen in clinical practice. Comminuted intra articular fractures are usually associated with road traffic accidents, fall from height in young patients. In old age groups it is associated with severe osteoporosis due to trivial fall. All intra articular fractures need good reduction for better functional outcome. K-wire fixation with plaster application, open reduction and internal fixation with locking plate, external fixator application (Ligamentotaxis) are various described methods for treating this fractures. When there is severe commination k-wires and screws cannot perch age the small fragments and there is high chances of loss of reduction. Also when there is severe soft tissue swelling and in case of open fractures open reduction and internal fixation is not possible.

Materials and Methods: This is a prospective study conducted in our hospital from January 2017 to October 2018. Inclusion criteria include close and open comminuted intra-articular fractures of distalradius in skeletally mature patients. All patients treated by Ligamentotaxis (external fixator application). Exfix removal done after six weeks and started on physiotherapy. Every patient functional outcome assessed 4months after exfix removal using Mayo wrist scoring.

Results: Overall 30 patients of comminuted intra-articular distal radius fractures treated by Ligamentotaxis. Non dominant hand involved in 10 patients and dominant hand involved in 20 patients. All patients under went removal of exfix after 6 weeks of application. All patients subjected to vigorous physiotherapy after exfix removal for 3 weeks. Functional outcome of every patient measured using mayo wrist score 4 months after exfix removal. Overall together the average mayo wrist score of operated wrist was 82 with excellent results in $46.66 \%$ of cases, good results in $36.66 \%$ of cases and satisfactory results in $10 \%$ of cases, poor results in $6.66 \%$ cases with a very significant p-value of $<0.0001$ using paired t-test.

Conclusion: Ligamentotaxis is safe and effective method of treatment for comminuted intra articular distal radius fracture. Can be practiced by any orthopedic surgeon even in small hospitals. Best suited for open fracture, severe commination and soft tissue compromise.

Keywords: Intra-articular, distal radius fractures, managed, Ligamentotaxis

\section{Introduction}

The fracture of lower end radius is the most common fracture constituting $17 \%$ of all fractures. The fracture is mainly due to road traffic accidents and fall from height in young age group and fall on outstretched hand in old age group with osteoporosis. The age specific incidence of distal radius fracture as stated by various authors has been ranged from 9 to 100 per 10,000 per year ${ }^{[1]}$. Various surgical options available to treat these fractures are k-wire fixation with cast application, external fixator application with or without $\mathrm{k}$-wires and open reduction and internal fixation with locking plate ${ }^{[2]}$. Various studies have reported excellent out comes with locked volar plating ${ }^{[3]}$ and external fixator (ligament taxis) ${ }^{[4]}$.

Volar fixed angle locking plates are an effective treatment for intra articular distal radius fractures allowing early postoperative rehabilitation ${ }^{[5]}$. However fixation of plate with screws not possible in case of severe comminution where getting perchase of small fragment with screw not possible. Also in case of severe soft tissue swelling and open fractures it is not possible to go for open reduction and fixation. Fixation of the volar plate in severely comminuted distal radius fracture may lead to poor purchase on the cancellous fragments and eventually lead to loss of reduction and loosening of screws. Gerostathopoulos et al recommend volar fixation in less comminuted fractures ${ }^{[6]}$. 


\section{Material and Methods}

The present study is conducted in the department of orthopedics in our medical college hospital between January 2017 to October 2018. The study includes all comminuted intra articular distal radius fractures both open and closed in the age group of 20 to 60. Most of the cases are three and four part fractures of melone classification ${ }^{[7]}$.

All the cases are immediately splinted in below elbow slab and surgery performed on next day after pre an aesthetic work-up. The cases underwent external fixator application with or without supplimentory k-wires under image guidance. All cases followed up weekly with radiographs for first three weeks. External fixator removal done after six weeks in outpatient department after checking with radiograph for union. Patient started on intensive physiotherapy for 3 weeks followed by wrist exercises by patient himself for further 6 weeks. All patients assessed at the end of 4 months by mayo wrist scoring ${ }^{[8]}$ and compared with normal side.

Mayo wrist score

\begin{tabular}{|c|c|}
\hline Section 1-Pain intensity & Section 2-Functional status \\
\hline No pain-25 & Return to regular employment-25 \\
\hline Mild occasional-20 & restricted employment-20 \\
\hline Moderate, tolerable-15 & able to work but unemployed-15 \\
\hline Severe to intolerable-0 & unable to work because of pain-0 \\
\hline $\begin{array}{c}\text { Section 3-Range of motion (\% } \\
\text { normal or degrees) }\end{array}$ & $\begin{array}{c}\text { Section 4-Grip strength (\% } \\
\text { normal) }\end{array}$ \\
\hline 100\% or 120 degree - 25 & $100 \%-25$ \\
\hline $75-99 \%$ or $90-120$ degrees-15 & $75-100 \%-15$ \\
\hline $50-74 \%$ or $60-90$ degrees-10 & $50-75 \%-10$ \\
\hline $25-49 \%$ or $30-60$ degrees-5 & $25-50 \%-5$ \\
\hline $0-24 \%$ or $<30$ degrees-0 & $0-25 \%-0$ \\
\hline
\end{tabular}

\section{Interpretation of overall score}

Score 90-100 - excellent

Score 80-90 - good

Score 60-80 - satisfactory

Score $<60$ - poor

\section{Observation and results}

The following observations were made from the data during our study.

Sex distribution of fracture

\begin{tabular}{|c|c|}
\hline Male & 20 \\
\hline Female & 10 \\
\hline
\end{tabular}

Males are more involved than female's 2:1 ratio because of more RTA cases involving males.

Side of involvement

\begin{tabular}{|c|c|}
\hline Dominant hand & 20 \\
\hline Non dominant hand & 10 \\
\hline bilateral & 0 \\
\hline
\end{tabular}

Dominant hand involved more commonly than non-dominant hand.

Age distribution

\begin{tabular}{|c|c|}
\hline Below 40 years & 10 \\
\hline 40-60 years & 12 \\
\hline Above 60 years & 8 \\
\hline
\end{tabular}

Our study includes age group ranging from 19 to 66 with average age 30.6 years.

Open vs close fracture

\begin{tabular}{|c|c|}
\hline Open fracture & 8 \\
\hline Closed fracture & 22 \\
\hline
\end{tabular}

In our study the distribution of closed verus open fracture was 2.7:1
Mode of injury

\begin{tabular}{|c|c|}
\hline Road traffic accidents & 12 \\
\hline Fall from height & 8 \\
\hline Fall on outstretched hand & 10 \\
\hline
\end{tabular}

Most common cause of fracture is RTA, Followed by fall on outstretched hand and fall from height.

Functional outcome of non-dominant hand

\begin{tabular}{|c|c|c|c|c|}
\hline Total number of cases & excellent & good & satisfactory & Poor \\
\hline 10 & 6 & 3 & 1 & 0 \\
\hline
\end{tabular}

Functional outcome of non-dominant hand wrist fractures using mayo wrist score showed excellent results in $60 \%$ cases, good results in $30 \%$ cases, satisfactory results in $10 \%$ cases.

Functional outcome of dominant hand

\begin{tabular}{|c|c|c|c|c|}
\hline $\begin{array}{c}\text { Total number of } \\
\text { cases }\end{array}$ & excellent & good & satisfactory & Poor \\
\hline 20 & 8 & 8 & 2 & 2 \\
\hline
\end{tabular}

Functional outcome of dominant hand wrist fractures using mayo wrist score showed excellent results in $40 \%$ cases, good results in $40 \%$ cases, satisfactory results in $10 \%$ cases and poor results in $10 \%$ of cases.

Overall results of 30 operated cases

\begin{tabular}{|c|c|c|}
\hline Result & No. of cases & Percentage \\
\hline excellent & 14 & 46.66 \\
\hline Good & 11 & 36.66 \\
\hline satisfactory & 3 & 10 \\
\hline Poor & 2 & 6.66 \\
\hline
\end{tabular}

Overall together comminuted intra articular distal radius fractures treated by external fixator application shows excellent results in $46.66 \%$ cases, good results in $36.66 \%$ cases satisfactory results in $10 \%$ cases and poor results in $6.66 \%$ of cases.

Statistical analysis by paired t-test

\begin{tabular}{|c|c|c|c|c|c|c|}
\hline $\begin{array}{c}\text { Total } \\
\text { number } \\
\text { of cases }\end{array}$ & $\begin{array}{c}\text { Total mayo wrist } \\
\text { score Operated } \\
\text { side }\end{array}$ & mean & $\begin{array}{c}\text { Total mayo } \\
\text { wrist score } \\
\text { Normal side }\end{array}$ & mean & t-value & p-value \\
\hline 30 & 2460 & 82 & 3000 & 100 & 9.98 & $<0.0001$ \\
\hline
\end{tabular}

Overall 30 cases of comminuted intra articular distal radius fractures treated by external fixator application. Functional outcome accessed using mayo wrist scoring system comparing with non injured hand showed mean mayo wrist score of 82 in operated wrist compared with mean mayo wrist score of non-injured side of 100 . The $\mathrm{p}$-value using paired $\mathrm{t}$ test is $<0.0001$ which is statistically very significant.

\section{Complications}

In our study 2 patients developed pin tract infection, one patient developed reflex sympathetic dystrophy and one patient needed redo because of loss of reduction. None of patients developed finger stiffness.

\section{Discussion}

80 percent of axial loads at the wrist are supported by distal end of the radius and 20 percent by triangular fibrocartilage and distal end of ulna [9]. The use of external fixation and pinning has demonstrated successful outcome in multiple studies ${ }^{[10]}$. Cooney et al ${ }^{[11]}$ demonstrated $90 \%$ good and excellent results in their review of external fixation and pinning for unstable distal radius fractures. 
Several prospective studies have included external fixation and various methods of fixation. Hutchinson et al [12] prospectively evaluated external fixation and pins with plaster technique. The external fixation group was better at maintaining radial length long-term. McQueen et al [13] prospectively evaluated the treatment of distal radius fractures that had lost their reduction after closed treatment and further managed by open reduction and bone grafting in one group and closed reduction and external fixator application in other group. Despite improved radiographic appearance in open reduction group, clinical outcomes same in both groups. Kreder et al ${ }^{[14]}$ published prospective multi center evaluation comparing external fixation and open reduction and internal fixation. They concluded that external fixation group had a more rapid return to function and better overall outcome than open reduction and internal fixation group.

Wright et al ${ }^{[15]}$ compared results of unstable distal radius fractures treated with external fixation group and fixed angle volar plate group. The authors conclude that patient rated wrist evaluation and DASH scores for both groups were stastistically equilant. Intraarticular step-off, volar tilt, radial length and ulnar variance were better in ORIF group, yet failed to reach statistical significance.

Marco Rizzo et al ${ }^{[16]}$ compared locked volar plating versus pinning and external fixation in the treatment of unstable intra articular distal radius fractures. They concluded that locked volar plating compares favorably to external fixation for amenable fracture patterns. Whereas grip and range of motion data were similar, DASH scores, frequency of rehabilitation, and some radiographic parameters were superior in patients treated with ORIF.

In our study also functional outcome of comminuted intraarticular distal radius fractures treated by external fixation has got good results even though radiologically inferior to volar locking plate fixation. Radiologically also radial length, radial inclination regained. But palmar tilt unable to regain with this method of fixation as stated by previous studies. The average wrist movements were 60 degree palmar flexion, 70 degree dorsiflexion achieved by this method of external fixation. The limitations of our study is sample size is medium, and it is short term study.

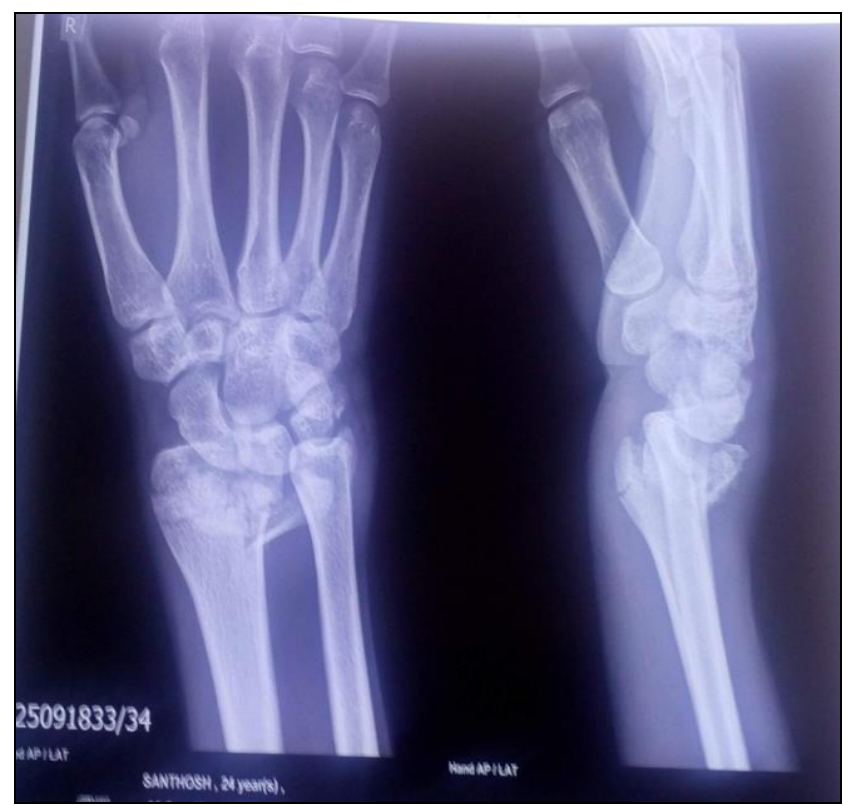

Case of comminuted intra articular distal radius fracture

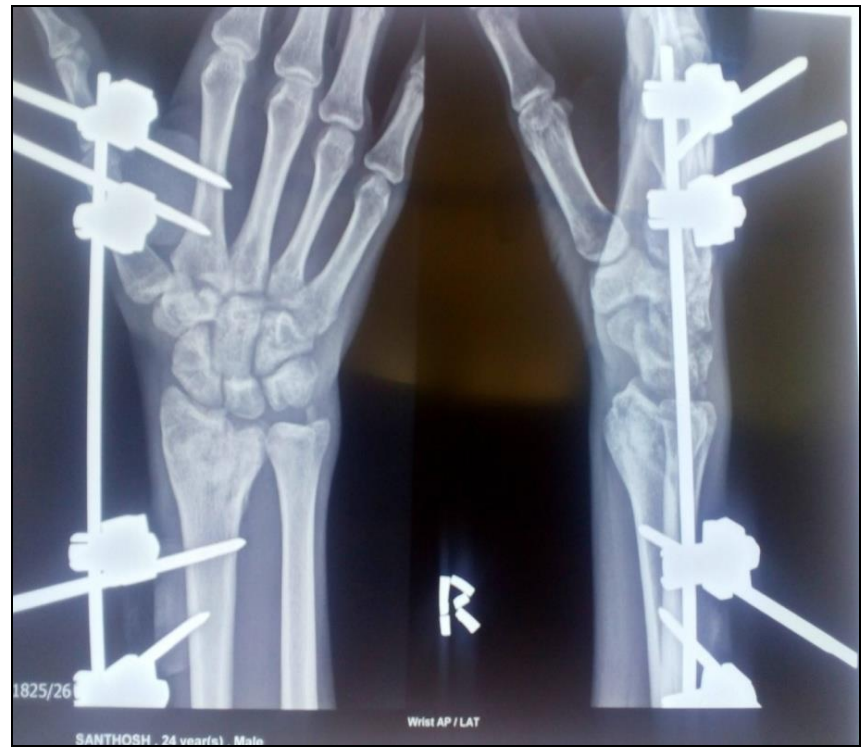

6 weeks followup

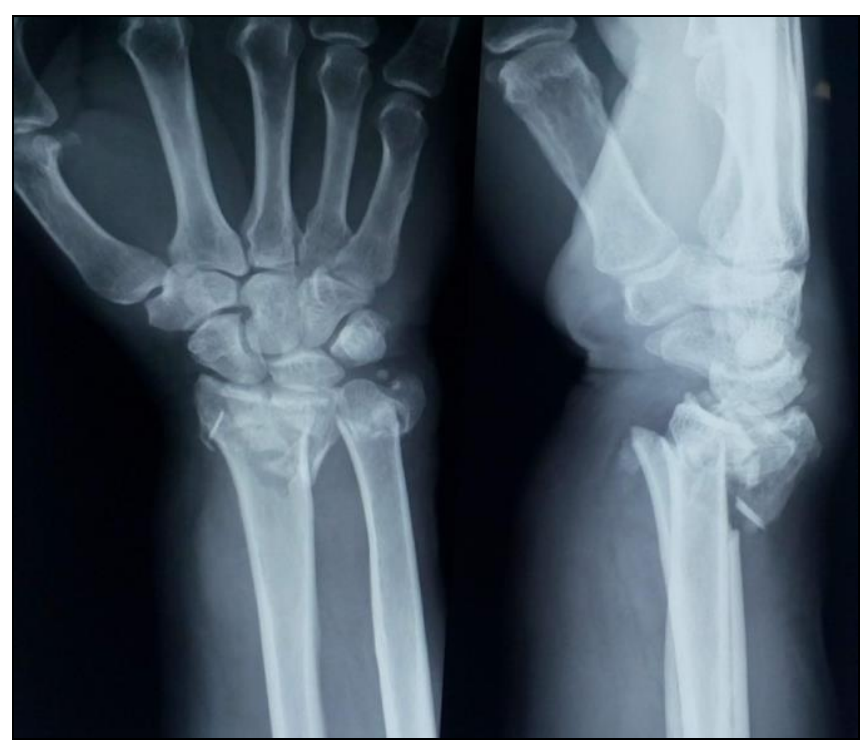

External fixator with k-wires.

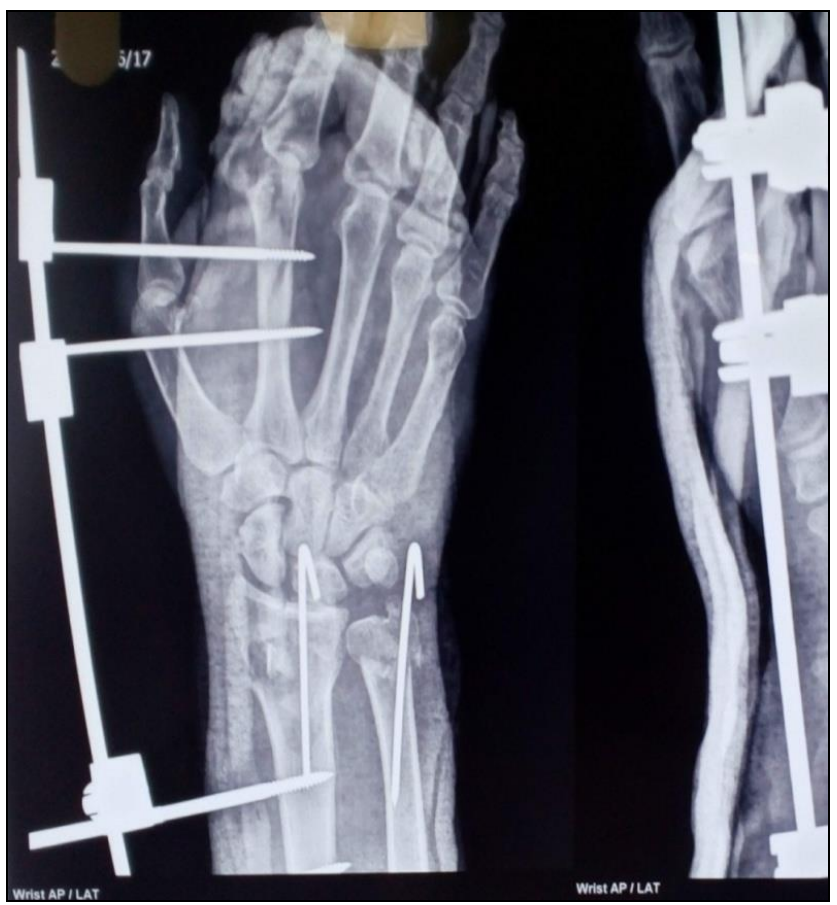

Palmar flexion 


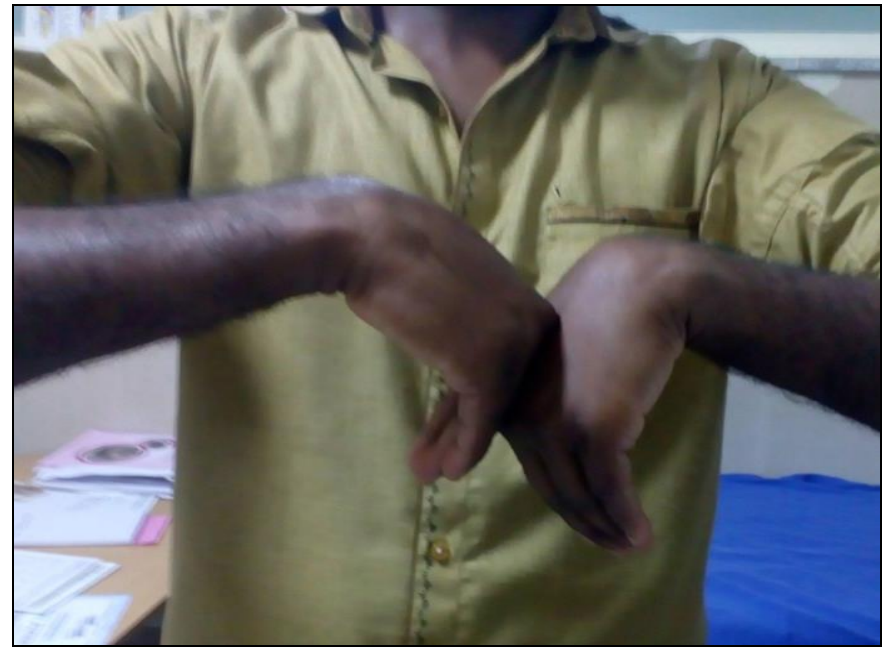

Dorsiflexion
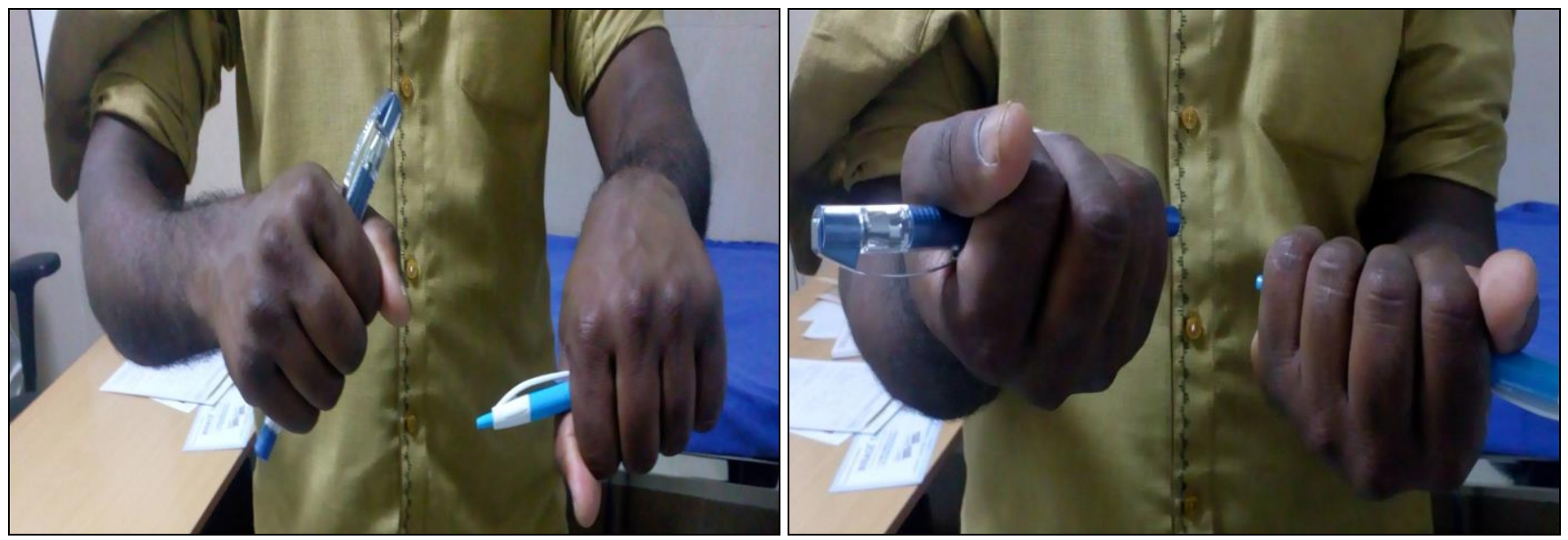

Supination
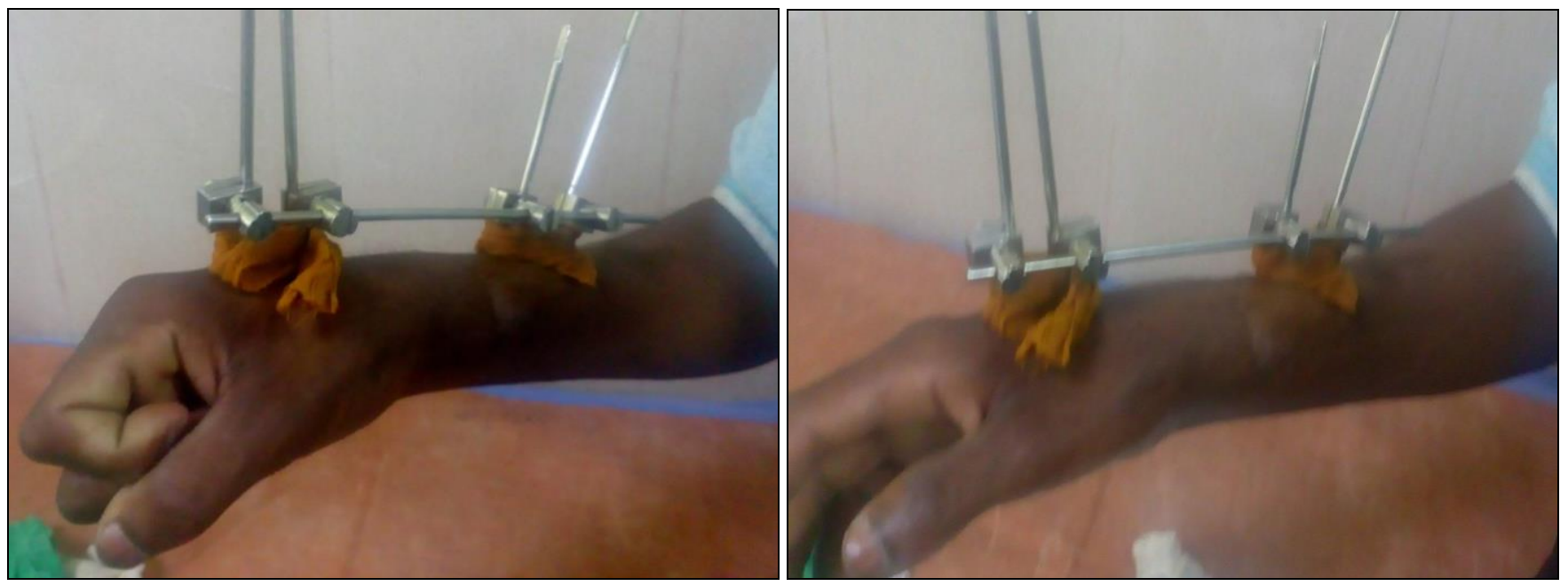

Finger mobilization immediate post op

\section{Conclusion}

We conclude that external fixation for comminuted intra articular distal radius fractures is safe and effective treatment. It is more suitable for cases where ORIF not possible because of severe comminution, soft tissue problems.

\section{References}

1. Larsen CF, Lauritsen J. Epidemiology of acute wrist trauma. Int J Epidemiology. 1993; 22:911-6.

2. Chen NC, Jupiter JB. Management of distal radius

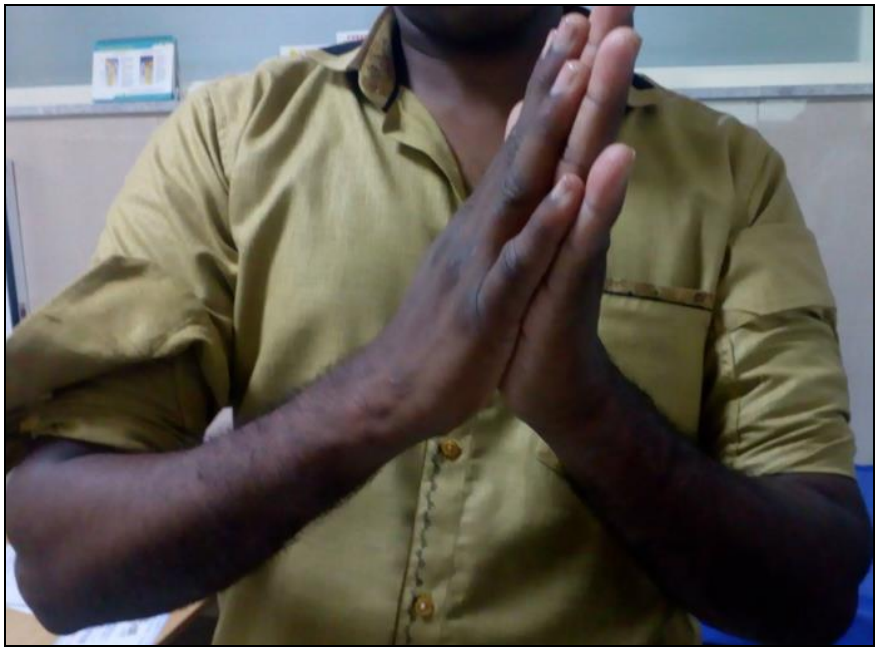

Pronation 
6. Gerostathopoulos N, Kalliakmanis A, Fandridis E, Georgoulis S. Trimed fixation system for displaced fractures of the distal radius. J Trauma. 2007; 62:913-8.

7. Melone CP Jr. Articular fractures of the distal radius. Orthop Clin North Am. 1984; 15:217-36.

8. WP Cooney, R Bussey, JH Dobyns, RL Linscheid. Difficult wrist fractures, Peri lunate fracture dislocations of the wrist. Clinical Orthopaedic and Related Research. 1987; 214:136-147.

9. Palmer AK. The Distal Radioulnar Joint. Anatomy, Biomechanics and Triangular Fibrocartilage Complex Abnormalities. Hand Clin. 1987; 3:31-40.

10. Harley BJ, Scharfenberger A, Beaupre LA et al. Augmented external fixation versus percutaneous pinning and casting for unstable fractures of the distal radius- a prospective randomized trial. J Hand Surg Am. 2004; 29:815-24.

11. Cooney WP $3^{\text {rd }}$, Linscheid RL, Dobyns JH. External pin fixation for unstable colles fracture. J Bone Joint Surg Am. 1979; 61:840-5.

12. Hutchinson DT, Strenz GO, Cautilli RA. Pins and plaster vs externalfixation in the treatment of unstable distal radial fractures. Arandomized prospective study. J Hand Surg Br. 1995; 20:365-72.

13. Mc Queen MM, Hajducka C, Court Brown CM. Redisplaced unstable fractures of the distal radius: a prospective randomized comparison of four methods of treatment. J Bone Joint Surg Br. 1996; 78:404-9.

14. Kreder HJ, Hanel DP, Agel J etal. Indirect reduction and percutaneous fixation versus open reduction and internal fixation for displaced intra articular fractures of the distal radius: a randomized, controlled trial. J Bone Joint Surg Br. 2005; 87:829-36.

15. Wright TW, Horodyski M, Smith DW. Functional outcome of unstable distal radius fractures: ORIF with a volar fixed angle tine plate versus external fixation. J Hand Surg Am. 2005; 30:289-99.

16. Rizzo M, Katt BA, Carothers JT. Comparision of locked volar plating versuspinning and externalfixation in the treatment of unstable intra articular distal radius fractures. Hand (NY). 2008; 3:111-7. 